\title{
SISTEM INFORMASI CUSTOMER RELATIONSHIP MANAGEMENT (CRM) BERBASIS KOMPUTER PADA AL BAIT TOUR AND TRAVEL
}

\author{
Eka Nurjannah ${ }^{1}$, Lena Magdalena ${ }^{2}$, Muhammad Hatta ${ }^{3}$ \\ Universitas CIC Cirebon ${ }^{1,2,3}$ \\ J1. Kesambi 202, Kota Cirebon, Jawa Barat. \\ ekanurjannah0405@gmail.com ${ }^{1}$, lena.magdalena@cic.ac.id ${ }^{2}$, muhammad.hatta@cic.ac.id ${ }^{3}$
}

\begin{abstract}
ABSTRAK
Saat ini sebagian besar perusahaan travel masih menggunakan sistem lama untuk mencatat hasil transaksi dan pengolahan datanya masih dalam bentuk manual sehingga dengan sistem yang lama dapat memerlukan waktu yang relatif lama dan lambat. Pada sistem lama perusahaan masih menggunakan sistem pengolahan data dengan menggunakan sistem berupa microsof exel maupun microsof word oleh sebab itu tidak dapat melakukan hubungan secara terus-menerus kepada pelanggan. Hal ini menimbulkan masalah dikarenakan pelanggan tidak dapat membantu pemasaran produk yang dimiliki perusahaan, dan akhirnya terjadi penurunan penghasilan dari perusahan. Selain itu juga dengan perkembangan teknologi yang semakin pesat saat ini dalam persaingan bisnis muncul permintaan pelanggan yang bermacam-macam serta kualitas dan pelayanan yang diberikan suatu perusahaan merupakan level of excellence yang sangat dibutuhkan pelanggan. Oleh sebab itu perusahaan akan menerapkan Customer Relationship Management $(C R M)$, Customer Relationship Management (CRM) adalah merupakan salah satu strategi dalam bisinis untuk mengelola hubungan dengan konsumen/pelanggan. Travel and tour ini mulai menyadari perlunya perubahaan dalam interaksi dengan kosuen. Penelitian ini bertujuan untuk informasi yang terintegrasi untuk pelayanan yang memuaskan pada konsumen dan kepuasaan hubungan pelanggan, Agar dapat mengolala data data konsumen secara kompterisasi. Dan Menghasilkan keuntungan pemasaran dan interaksi konsumen yang lebih efektif menghemat biaya dan tenaga. Pada penelitian ini CRM yang akan dibangun melibatkan Petugas yang terlibat yaitu admin, bendahara dan trakhir direktur bertugas untuk melihat hasil laporan. Dengan penggunaan sistem management pelanggan menggunakan metode Customer Relationship Management (CRM) dapat menarik pelanggan baru dan mempertahankan pelanggan yang telah ada agar dapat membantu setiap proses pemasaran yang dilakukan oleh perusahaan.
\end{abstract}

Kata Kunci : Informasi, Management, CRM, Konsumen, Travel.

\section{Abstract}

Currently, most travel companies still use the old system to record the results of transactions and the data processing is still in manual form so that the old system can require a relatively long time and slow. In the old system the company still used a data processing system using a system in the form of microsoft exel and microsof word and therefore could not make a continuous relationship to customers. This causes problems because customers cannot help marketing the company's products, and eventually a decline in income from the company. In addition, with the rapid development of technology today in business competition emerging diverse customer demand and the quality and service provided by a company is a level of excellence that is needed by customers. Therefore the company will implement Customer Relationship Management (CRM), Customer Relationship Management (CRM) is one of the strategies in the business to manage relationships with consumers / customers. Travel and tour is starting to realize the need for change in interaction with consumers. This study aims at integrated information for satisfying services to consumers and customer relationship satisfaction, in order to manage customer data in a compteralized manner. And Generate marketing benefits and more effective customer interaction saving costs and effort. In this research, the CRM that will be built involves the Officers involved, namely

Sistem Informasi Customer Relationship Management (CRM) berbasis komputer pada Al Bait Tour And Travel -( Eka Nurjannah, Lena Magdalena, Muhammad Hatta) 
the admin, treasurer, and finally the director in charge of seeing the results of the report. With the use of a customer management system using the Customer Relationship Management (CRM) method, it can attract new customers and retain existing customers in order to help each marketing process carried out by the company.

\section{Keywords : information, Management, CRM, Customer, Travel}

\section{Pendahuluan}

Perjalaan umroh yakni salah satu ibadah yang mempunyai kedudukan tinggi dalam islam, Ibadah ini hampir mirip dengan ibadah haji hanya saja dalam umroh tidak ada wukuf, mabit dan melontar jumrah. Maka diperlukannya biro perjalanan umroh untuk melaksanankan ibadah spritual, Al Bait Tour And Travel yang berdiri tahun 2017 yang beralamat di desa banjar wagunanan kab cirebon. Merupakan perusahaan jasa pelayanan pariwisata spritual luar negeri khususnya layanan umrah dan perjalanan wisata sejarah Islam ke berbagai tempat bersejarah di dunia.

Customer Relationship Management (CRM) adalah sistem manajemen yang secara khusus menangani perusahaan dengan konsumen dengan tujuan meningkatkan nilai perusahaan dimata para konsumen. CRM melingkupi semua aspek yang behubungan dengan calon konsumen dan konsumennnya saat ini.

Pada Albait Tour and travel untuk pembagian tugas belum sesuai dengan job desk (double job) untuk suport pelayanan konsumennya. Sehingga pelanggan mengalami kesulitan untuk mendapatkan informasi dan juga belum menerapkan sistem informasi untuk pengelolaan data konsumen berakibat kurangnya pelayanan yang memuaskan. kelola paket umrah, jadwal, keberangkatan, pembayaran dan kelola laporan pembayaran serta laporan keberangkatan yang belum terkomputerisasi, sehingga rentan untuk kehilangan data. Yang dapat menyebabkan kerugian besar pada perusahaan.

\section{Kajian Pustaka}

2.1. Sistem

Sistem adalah suatu jaringan kerja dari prosedur prosedur yang saling berhubungan, berkumpul bersama sama untuk melakukan suatu kegiatan atau melakukan sasaran tertentu. [1]

\subsection{Informasi}

informasi adalah merupakan kumpulan dari perangkat keras dan perangkat lunak komputer serta perangkat manusia yang akan mengolah data menggunakan perangkat keras dan perangkat lunak tersebut.[2]

\subsection{CRM}

CRM adalah strategi bisinis inti yang memadukan proses dan fungsi internal, jaringan eksternal untuk menciptakan dan menyampaikan nilai kepada pelanggan untuk mendapatka keuntungan.[3]

\subsection{Al Bait Tour And Travel}

Al Bait Tour And Travel adalah Al Bait Tour And Travel adalah PT Putra Darul Ulum yang bergerak dalam bidang jasa perjalanan ibadah umroh, berdiri pada bulan Mei 2017 di desa banjar wangunan kab cirebon, Dengan tujuan memberikan pelayanan terbaik dengan nilai tambah manfaat kepada masyarakat dengan moto nya itu "Umroh Aman Dan Nyaman" sehingga bisa menjadi perusahaan yang terpercaya memberikan solusi kepada masyarakat dalam memenuhi kebutuhan jasmani dan rohani.

\subsubsection{Visi dan Misi}

Visi :

Menjadi Perusahaan terdepan dan terbesar di indonesia dalam bidang jasa pelayanan umroh terbaik yang dapat memberikan kontribusi nyata bagi masyarakat dengan moto "Umroh Aman Dan Nyaman"

Misi :

1. Menjadi Perusahaan yang selalu up to date dalam memberikan kenyaman dan keamanan konsumen yang akan melakukan perjalanan

2. Mengedepankan kepuasan konsumen

3. Menjadi Perusahaan layanan jasa one stop service for tour and travel yang tangguh dan unggu. 


\subsubsection{Struktur Organisasi Al Bait Tour And Travel}

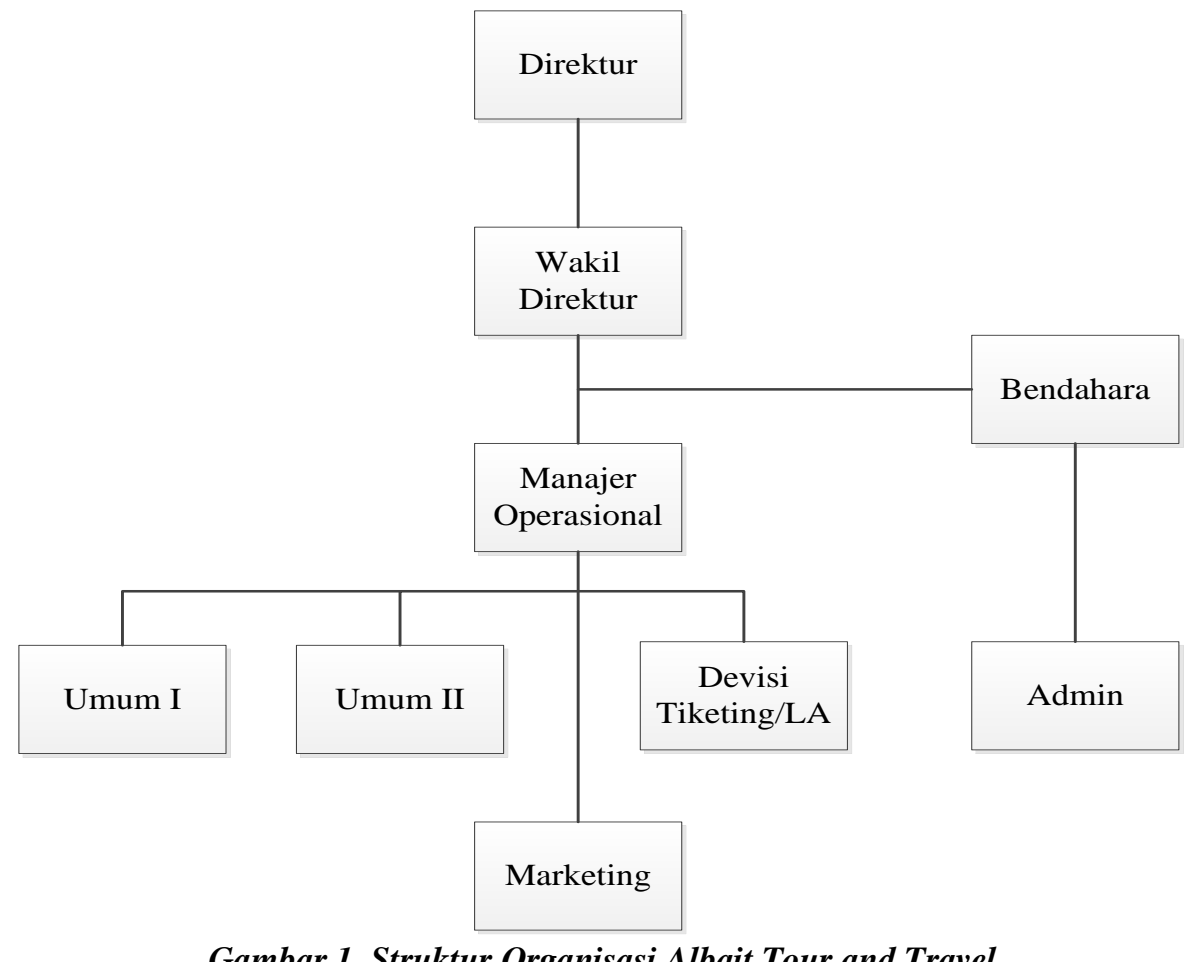

Gambar 1. Struktur Organisasi Albait Tour and Travel

\section{Perancangan}

\subsubsection{Flowcmap}

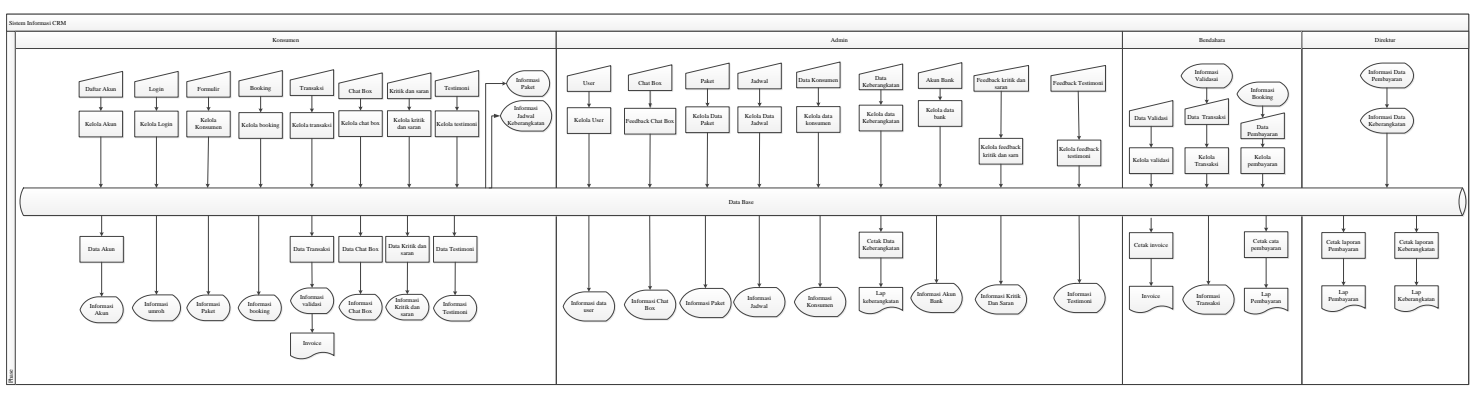

Gambar 2. Sistem Informasi Customer Relationship Management (CRM) berbasis komputer pada Albait Tour and Travel

Flowmap komputerisasi merupakan sistem informasi CRM pada al bait tour and travel yang mendeskripsikan penglolaan proses-proses menglola data konsumen dengan metode crm yang melibatkan beberapa entitas seperti konsumen, admin, bendahara dan direktur. 


\subsubsection{Diagram Konteks}

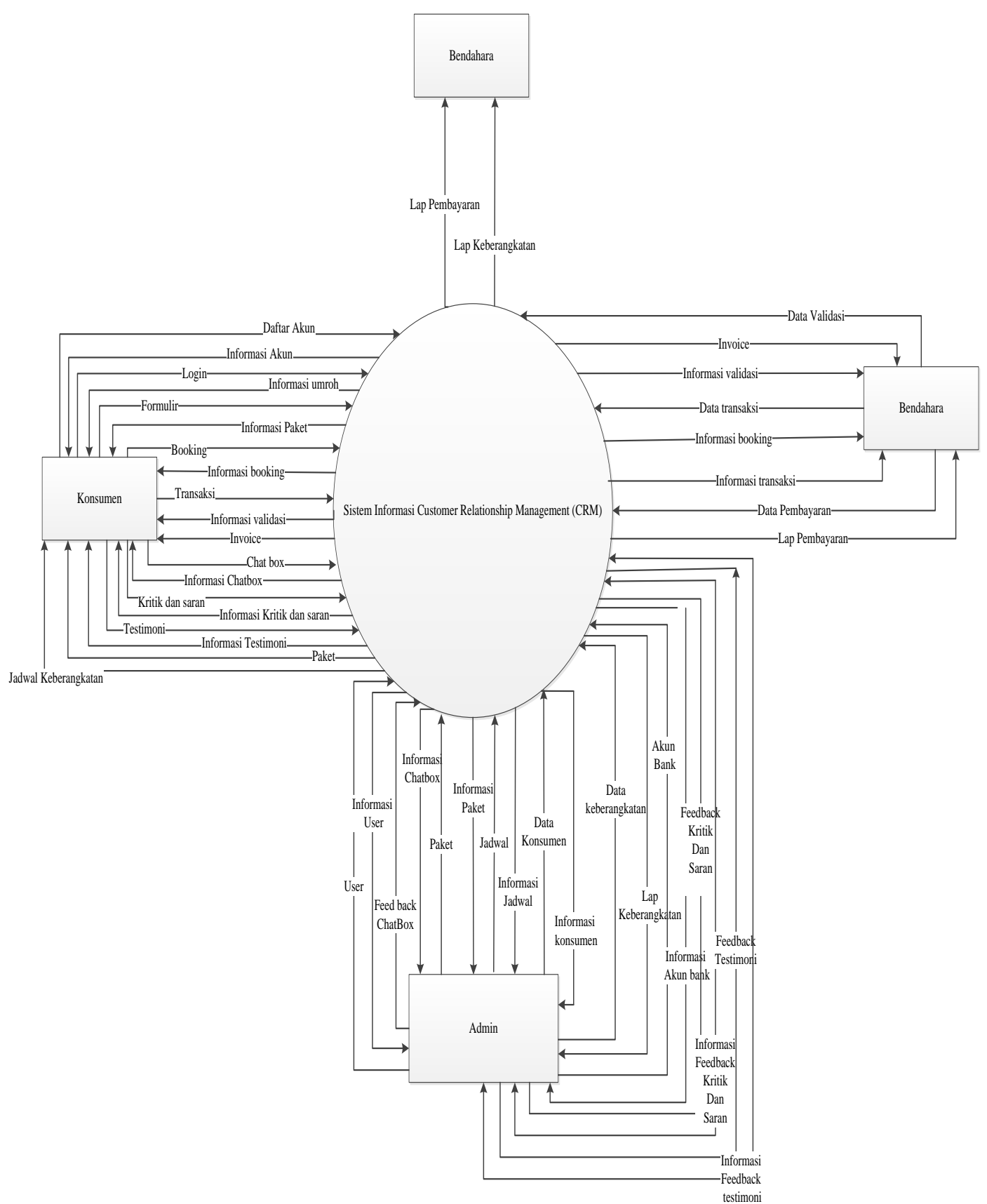

Gambar 3. Diagram Konteks Sistem Informasi Customer Relationship Management (CRM) berbasis komputer pada Albait Tour and Travel

Diagram konteks merupakan gambaran dari kegiatan seperti proses-proses pengelolaan data konsumen, data jadwal dan lain lain pada al bait tour and travel yang akan di terapkan pada sistem untuk menghasilkan sebuat laporan. 


\subsubsection{DFD Level 0}

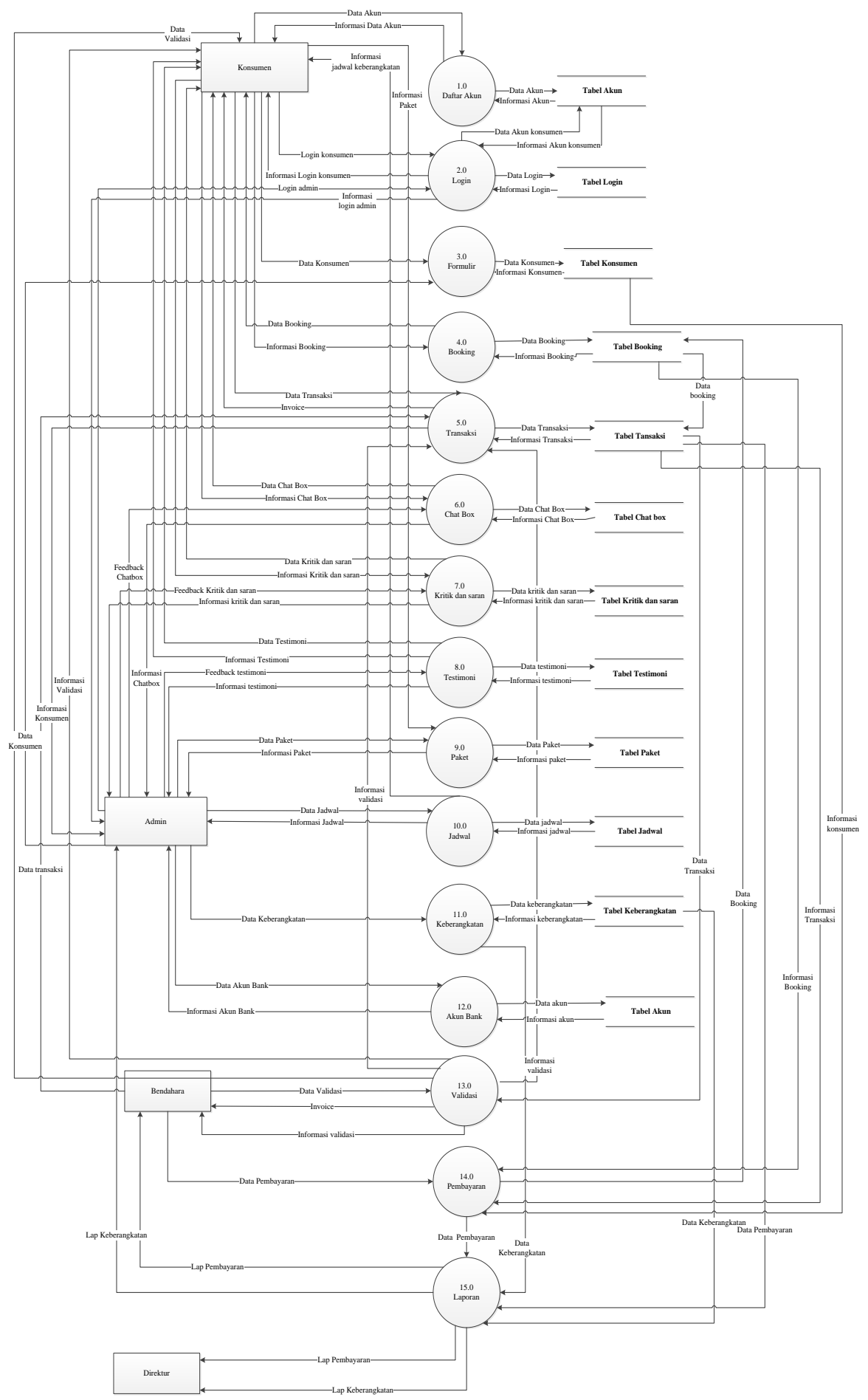

Gambar 4. DFD Level 0 Sistem Informasi Customer Relationship Management (CRM) berbasis komputer pada Albait Tour and Travel

Sistem Informasi Customer Relationship Management (CRM) berbasis komputer pada Al Bait Tour And Travel -( Eka Nurjannah, Lena Magdalena, Muhammad Hatta) 
Diagram level 0 merupakan diagram CRM yang mengambarkan proses dari data flow diagram. Diagram nol memberikan pandangan secara menyeluruh mengenai sistem yang ditangani, menunjukkan tentang fungsi-fungsi atau proses yang ada, aliran data, dan eksternal entity.

\subsubsection{DFD Level 1 Proses 1}

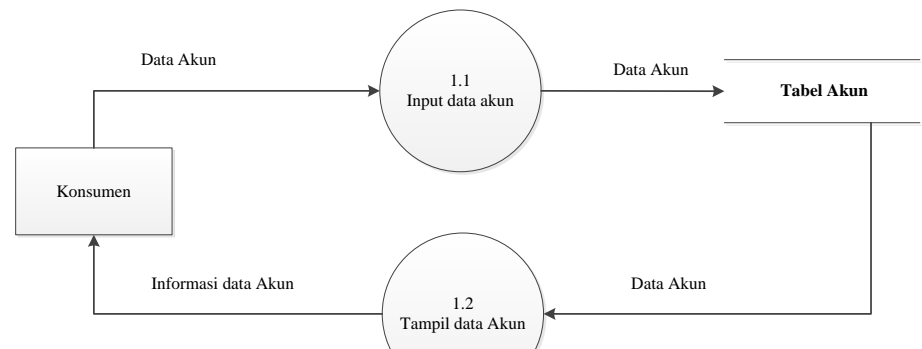

Gambar 5. Gambar Data Flow Diagram (DFD) level 1 proses ke 1 kelola data akun DFD level 1 merupakan proses dari konsumen untuk membuat akun / registrasi agar bisa login.

\subsubsection{DFD level 1 Proses 2}

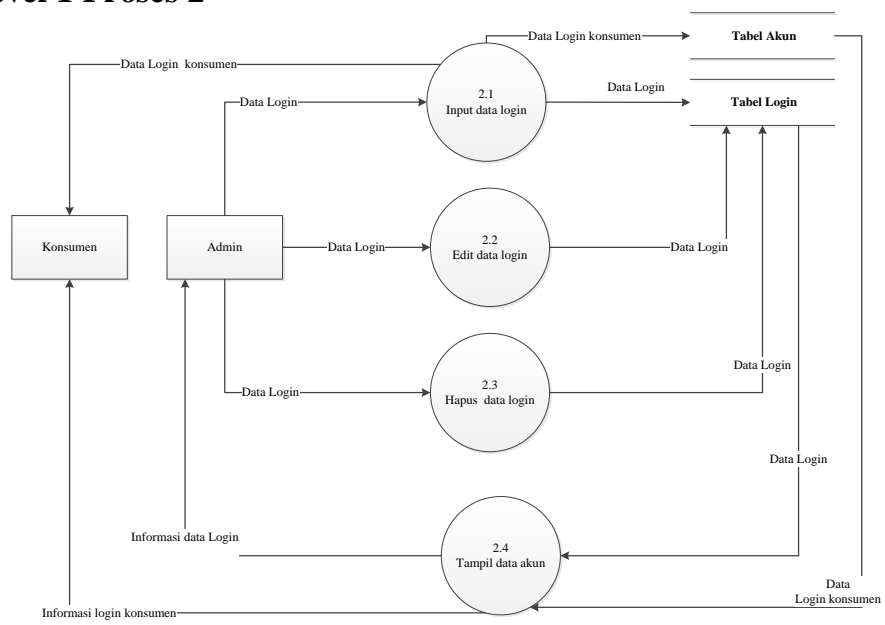

Gambar 6. Gambar Data Flow Diagram (DFD) level 1 proses ke 2 kelola data login

DFD level 1 proses 2 merupakan proses dari konsumen admin dan untuk mengkelola data user/ login agar bisa mengakses sistem dan bisa menggunakan fitur yang ada di sistem

\subsubsection{DFD Level 1 proses 3}

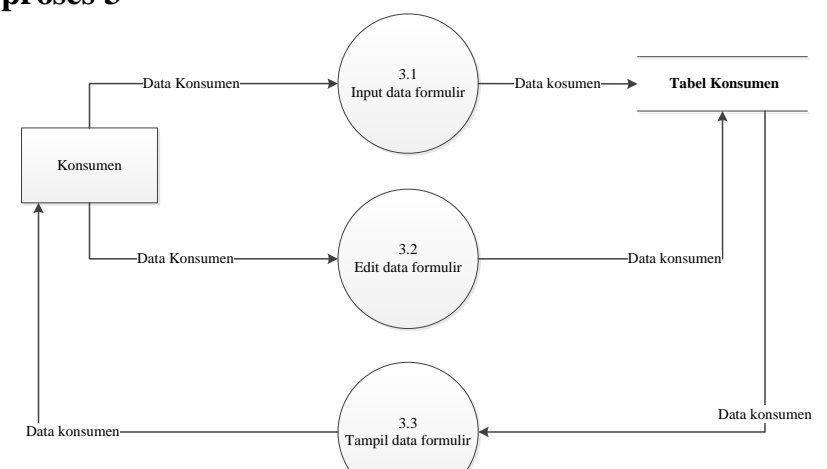

Gambar 7. Gambar Data Flow Diagram (DFD) level 1 proses ke 3 kelola data formulir

DFD level 1 proses 3 merupakan proses dari konsumen untuk mengkelola data formulir yang akan keluar output data konsumen yang ditampilkan ke sistem. 


\subsubsection{DFD Level 1 Proses 4}

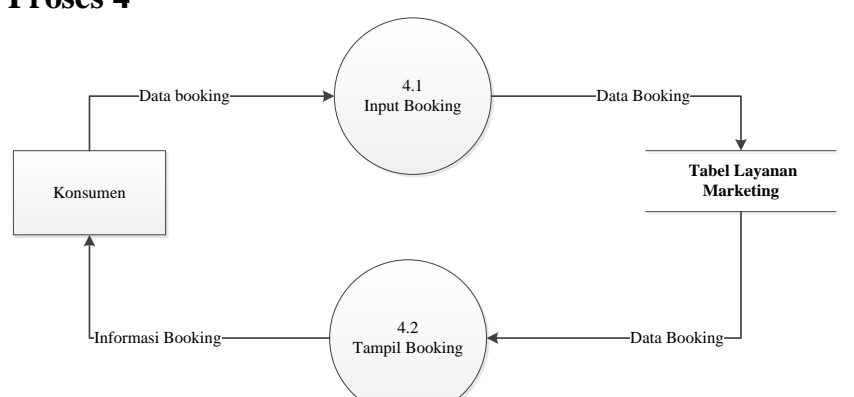

Gambar 8. Gambar Data Flow Diagram (DFD) level 1 proses ke 4 kelola data transaksi

DFD level 1 proses 4 merupakan proses dari konsumen untuk mengkelola data booking yang akan keluar output informasi booking untuk ditampilkan ke sistem.

\subsubsection{DFD level 1 Proses 5}

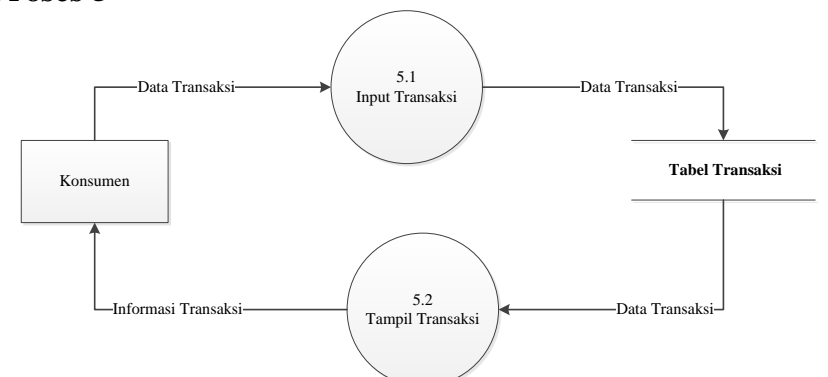

Gambar 9. Gambar Data Flow Diagram (DFD) level 1 proses ke 5 kelola data transaksi

DFD level 1 proses 5 merupakan proses dari konsumen untuk mengkelola data transaksi yang akan keluar output informasi transaksi yang ditampilkan ke sistem.

\subsubsection{DFD level 1 Proses 6}

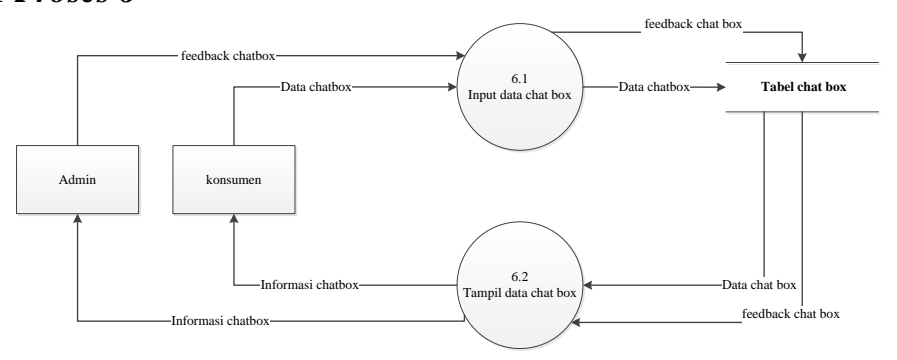

Gambar 10. Gambar Data Flow Diagram (DFD) level 1 proses ke 6 kelola data chat box

DFD level 1 proses 6 merupakan proses dari konsumen dan admin untuk mengkelola data chatbox yang akan keluar output informasi chatbox yang ditampilkan ke sistem. 


\subsubsection{DFD Level 1 Proses 7}

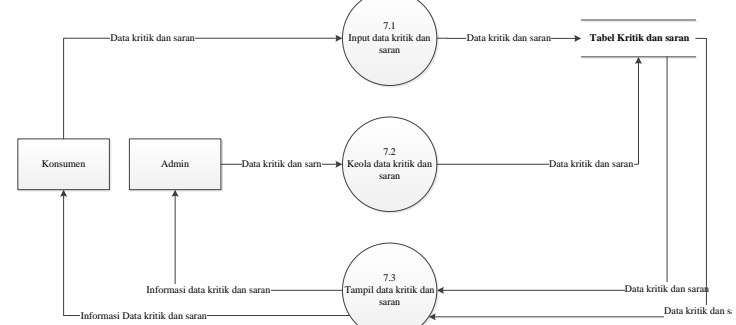

Gambar 11. Gambar Data Flow Diagram (DFD) level 1 proses ke 7 kelola data kritik dan saran

DFD level 1 proses 7 merupakan proses dari konsumen dan admin untuk mengkelola data kritik dan saran yang akan keluar output informasi kritik dan saran yang ditampilkan ke sistem.

\subsubsection{DFD Level 1 Proses 8}

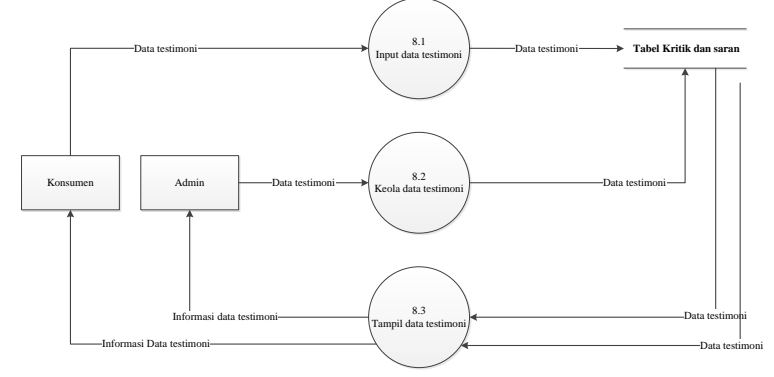

Gambar 12 Gambar Data Flow Diagram (DFD) level 1 proses ke 8 kelola data testimoni

DFD level 1 proses 8 merupakan proses dari konsumen dan admin untuk mengkelola data testimoni yang akan keluar output informasi testimoni yang ditampilkan ke sistem.

\subsubsection{DFD Level 1 Proses 9}

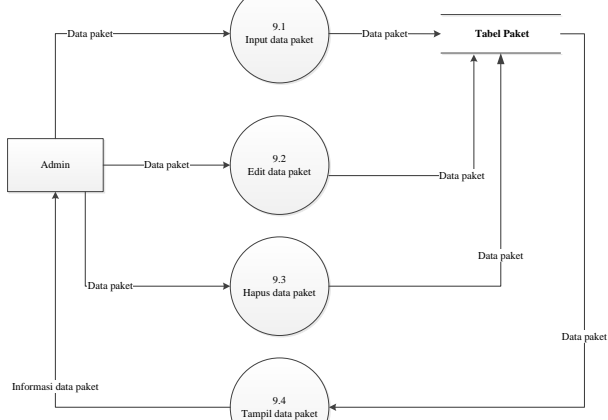

Gambar 13. Gambar Data Flow Diagram (DFD) level 1 proses ke 9 kelola data Paket

DFD level 1 proses 9 merupakan proses dari admin untuk mengkelola data paket yang akan keluar output informasi paket yang ditampilkan ke sistem. 


\subsubsection{DFD Level 1 Proses 10}

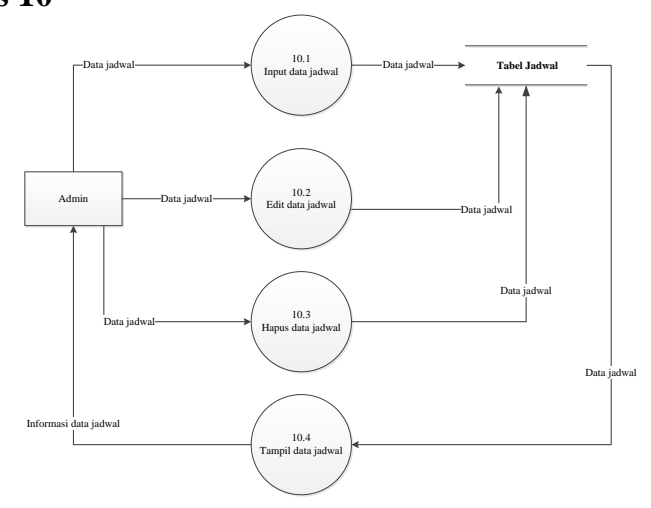

Gambar 14. Gambar Data Flow Diagram (DFD) level 1 proses ke 10 kelola data jadwal

DFD level 1 proses 10 merupakan proses dari admin untuk mengkelola data jadwal yang akan keluar output informasi paket yang ditampilkan ke sistem

\subsubsection{DFD Level 1 Proses 11}

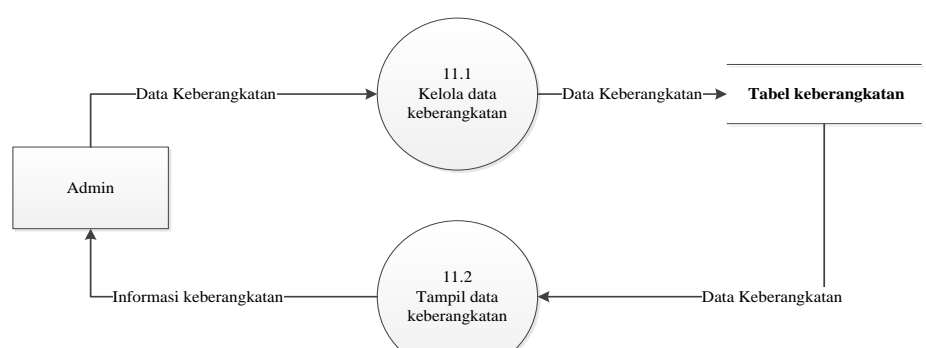

Gambar 15. Gambar Data Flow Diagram (DFD) level 1 proses ke 11 kelola data keberangkatan

DFD level 1 proses 11 merupakan proses dari admin untuk mengkelola data keberangkatan yang akan keluar output informasi keberangkatan yang ditampilkan ke sistem.

\subsubsection{DFD Level 1 Proses 12}

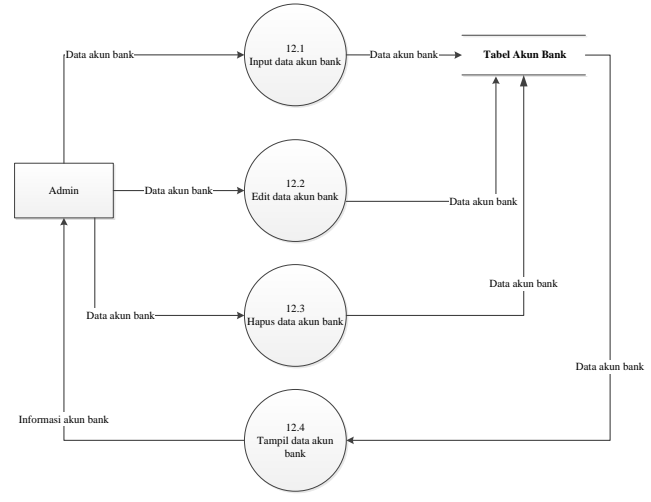

Gambar 16. Gambar Data Flow Diagram (DFD) level 1 proses ke 12 kelola data akun bank

DFD level 1 proses 12 merupakan proses dari admin untuk mengkelola data akun bank yang akan keluar output informasi akun bank yang ditampilkan ke sistem. 


\subsubsection{DFD Level 1 Proses 13}

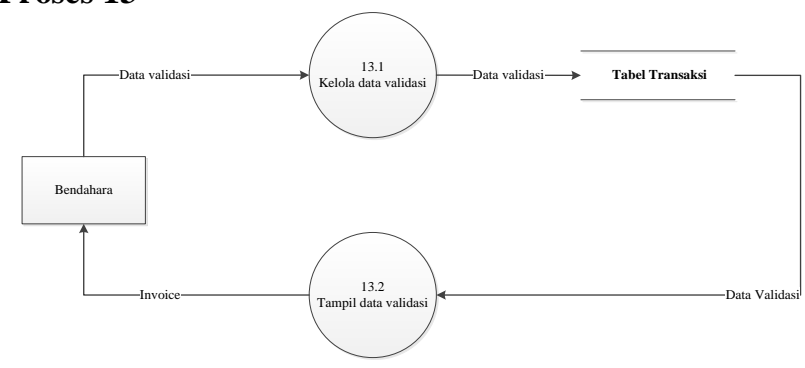

Gambar 17. Gambar Data Flow Diagram (DFD) level 1 proses ke 13 kelola data validasi

DFD level 1 proses 13 merupakan proses dari bendahara untuk mengkelola data validasi yang akan keluar output invoice yang ditampilkan ke sistem.

\subsubsection{DFD Level 1 Proses 14}

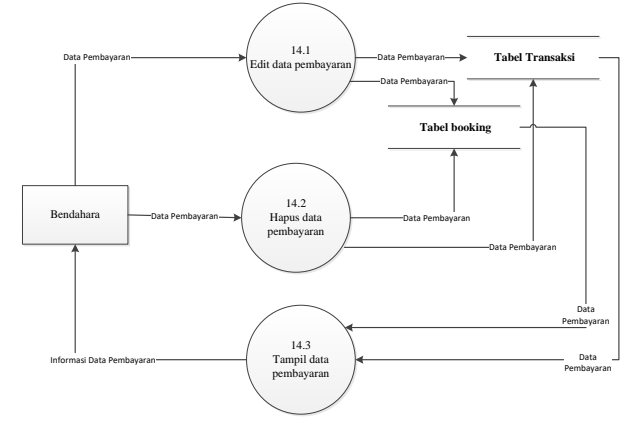

Gambar 18. Gambar Data Flow Diagram (DFD) level 1 proses ke 14 kelola data pembayaran

DFD level 1 proses 13 merupakan proses dari bendahara untuk mengkelola data pembayaran yang di simpan di tabel booking dan tabel transaksi yang akan keluar output informasi data pembayaran yang ditampilkan ke sistem.

\subsubsection{DFD Level 1 Proses 15}

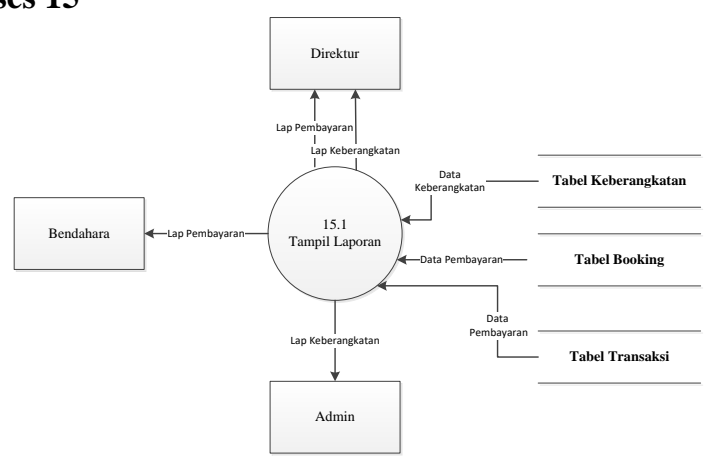

Gambar 19. Gambar Data Flow Diagram (DFD) level 1 proses ke 15 kelola data laporan

DFD level 1 proses 15 merupakan proses untuk mengkelola data laporan dari tabel keberangkatan dari admin tabel booking dan tabel transaksi dari konsumen yang akan keluar outputnya yaitu lap pembayaran dan lap keberankatan untuk direktur, lap keberangktan untuk admin dan lap pembayaran untuk bendahara yang ditampilkan ke sistem untuk bendahara. 


\section{Hasil Penelitiaan}

\subsection{Tampilan Halaman Web}

\subsubsection{Halaman Tampil Daftar Akun}

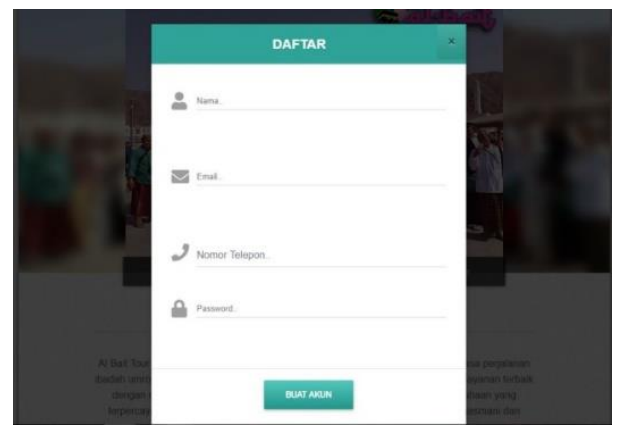

Gambar 19. Halaman Login User

Pada Gambar 19 berisikan tampilan daftar akun untuk user (konsumen). Yang berisi form input nama, email, nomer telepon, dan password.

\subsubsection{Halaman Tampil Login}

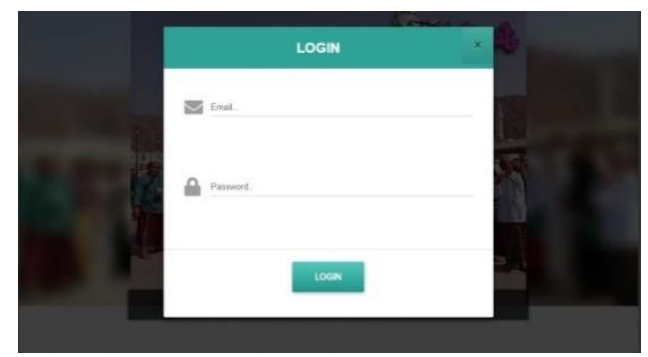

Gambar 20. Halaman Login User konsumen

Pada Gambar 20 berisikan tampilan Login untuk user (konsumen). Pada tampilan ini terdapat form input username dan password.

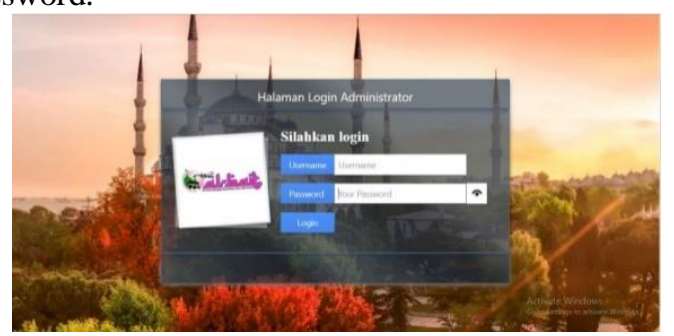

Gambar 21. Halaman Login User Admin Bendahara Direktur

Pada Gambar 21 berisikan tampilan Login untuk user (konsumen). Pada tampilan ini terdapat form input username dan password 


\subsubsection{Halaman Tampil Data Formulir}

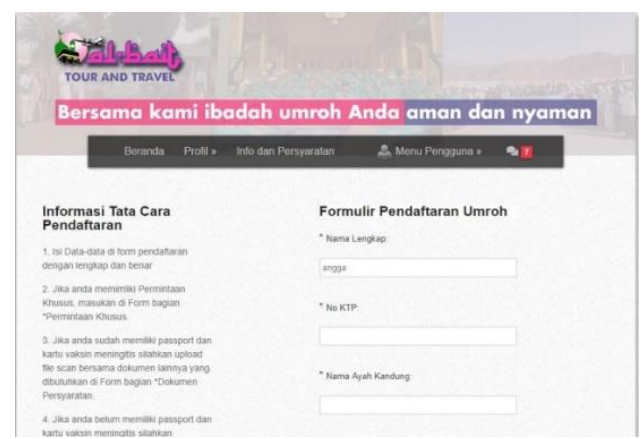

Gambar 22. Halaman Formulir

Pada Gambar 22 berisikan tampilan formulir untuk user (konsumen). Yang terdapat form nama lengkap, no ktp, nama ayah, tempat lahir, tanggal lahir, jenis kelamin, no pasport (jika sudah punya), masa berlaku, tanggal dikeluarkan, tempat dikeluarkan, kewarganegaraan, status, alamat, nomer telepon, email, pekerjaan, pendapatan, gol darah, ciri, permintaan khusus.

\subsubsection{Halaman Tampil Data Konsumen}

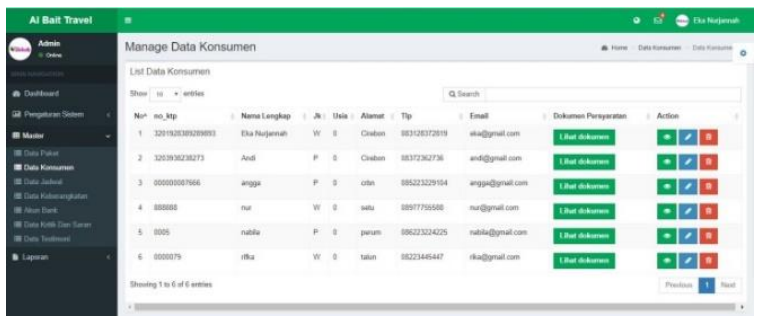

Gambar 23. Halaman Data Konsumen

Pada Gambar 23 berisikan tampilan data konsumen. Yang terdapat form no ktp,nama lengkap, jk, usia, alamat, tlpn, email, serta dokumen persyaratan.

\subsubsection{Halaman Tampil Data Pembayaran}

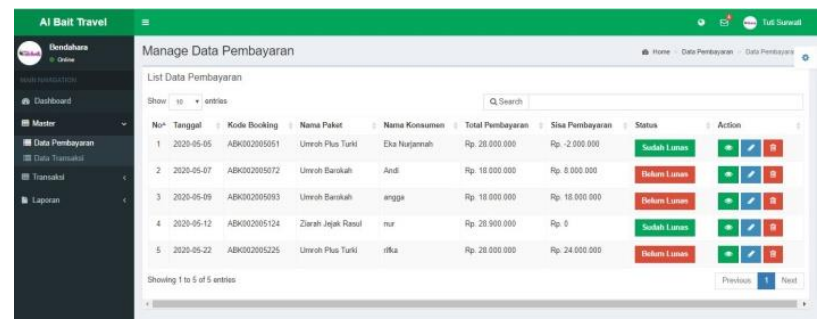

Gambar 24. Halaman Data Konsumen

Pada Gambar 24 berisikan tampil data pembayaran . Yang terdapat form no ktp,nama lengkap, $\mathrm{jk}$, usia, alamat, tlpn, email, serta dokumen persyaratan.

\section{KESIMPULAN}

1. Berdasarkan hasil penelitian dan analisa serta perancangan yang telah dilaksanakan, maka dapat ditarik beberapa kesimpulan yaitu:

2. Dengan adanya sistem perancangan ini al bait tour and travel mempunyai Aplikasi sistem informasi customer relationship management (CRM) berbasis computer.

3. Dengan dibuatnya sistem informasi customer relationship management (CRM) berbasis komputer pada al bait tour and travel, mempermudah pembagian tugas dalam melayani konsumen sehingga tidak adalagi double job.

4. Dengan adanya sistem informasi customer relationship management (CRM) data data konsumen terkelola secara komputerisasi. 


\section{DAFTAR PUSTAKA}

[1] Abdul K. 2014. Pengenalan Sistem Informasi.Edisi Revisi. Yogyakarta,

[2] Andri Kristanto. 2018. Perancangan Sistem Informasi Dan Aplikasi, Edisi Revisi, Yogyakarta Gava Media,

[3] Francis Buttle. 2014. Customer Relationship Management, Bayu Media Publishing, 